\title{
Social Support, Quality of life and Social health in Older Adults in Lorestan, Iran: A Structural Equation Modeling
}

\author{
Research Article
}

\section{Sina Hamed 1 , Mostafa Amini-Rarani², Mehdi Nosratabadi ${ }^{*}$}

1. Department of social welfare and Health, Isfahan University of Medical Sciences, Isfahan, Iran.

2. Health Management and Economics Research Centre, Isfahan University of Medical Sciences, Isfahan, Iran. 3. Social Determinants of Health Research Centre, Isfahan University of Medical Sciences, Isfahan, Iran.

\begin{abstract}
Objective: As Iran has started to experience population ageing, it is important to consider the elderly needs and health. The purpose of this study was to examine the structural relationships between social support, quality of life and social health in Iranian older adults. Method: The research was a survey-based cross-sectional study. The sample consisted of 800 non-institutionalized older adults living in Lorestan province in Iran in 2018. Three questionnaires were employed to collect data including social health, social support and quality of life. Data were analyzed by SPSS 22 and Amos 8 softwares. Results: The majority of the participants were men (51\%) and $62 \%$ of the participants were married. The most of older adults had moderate or poor economic status. Having insurance and higher income significantly correlated with higher quality of life and social health $(p<0.05)$. The direct effect of all three variables including social support on social health, and social support on quality of life and social health on quality of life were significant. The final model indicated that $39 \%$ of the overall variance of quality of life was attributed to social support and social health. Conclusion: Findings confirm the importance of social networks and services in the life of older adults. Indeed, to improve quality of life and social health, it is needed to pay much more attention to all aspects of social support.
\end{abstract}

Key Words: Social support, Quality of life, Social health.

\section{Introduction}

Ageing population has progressed furthest in developed countries but developing countries have also begun to experience considerable increases in their older adults $(1,2)$. Iran population is also getting older. Given the quality of life (QoL) and health can be easily threatened in the elderly period, it is potentially important to address the attributing factors. While the proportion of people with 60 years old and above in Iran was 5.4 percent in 1975 it will increase to 10.5 percent in 2025 and 21.7 percent in 2050 (3). According to Iran's National Census 2015, Lorestan province has 1760000 people, out of them, about 179000 people aged over the 60 years old. Namely, the average population of the older adults in this province is more than $10 \%$, which is higher than the average population of elderly people in the Iran (4). Thus, to promote elderlies' quality of life it is vital to anticipate requirements and address their growing needs (5).According to a survey, 25 to $30 \%$ of the elderly in Iran did not benefit from any medical insurance services(6). Therefore, many of

\section{* Corresponding Author:}

Mehdi Nosratabadi.

Social Determinants of Health Research Center,

Isfahan University of Medical Sciences, Isfahan, Iran,

Hezar Jerib Ave, 8174673461 Isfahan, Iran.

Email id - nosrat.welfare@gmail.com uninsured older adults are faced to difficulty in access to health care (7).

Studies have shown an association between increased levels of social support and reduced risk for physical disease, mental illness, and mortality(8) Social support includes real or perceived resources provided by others that enable a person to feel cared for, valued, and part of a network of communication and mutual obligation(9) Social support can be critical for those older adults who rely on family, friends, or organizations to assist them with daily activities, provide companionship, and care for their well-being.

Gallicchio (2007) showed that poor social networks are associated with worse physical and mental health and well-being(10). Other factors such as living in poor housing, inadequate finances and inadequate social relationships were also important factors leading to deterioration in social health and QoL(11). Farquhar (2009) reported that older people identified family relationship, health, standard of living, activities and other social contacts important to bring quality to their life(12).

Bowling also revealed that good health, good social relationship, having social activities, good financial circumstances and being independent significantly would increase QoL and social health in elderly populations (13). Alipour in Iran also revealed that good health, good social relationship, having social activities, good financial circumstances and being independent significantly would increase QoL in elderly 
populations (14) So, can be said that people with higher social support have better health and well-being.

In Iran older adults are treated very respectfully and they are privileged by a high position among the family members and are supported by their family for all their needs. The Islamic values also supported this belief. In Iran, while considerable decline appears in the health of the older adults through getting older, their ability to obtain their health needs seems even getting worse than before. It happens because most of older adults lost their income source in ageing period and become economically dependent to others. According to a survey, 25 to $30 \%$ of the older adults in Iran did not benefit from any medical insurance services(1). Therefore, thousands of old men and women are likely to face further hazards for their health in Iran. However, only a few studies have been conducted in Iran on different aspects of social life of older adults.

This study aimed to assess QoL, social health and social support in a sample of older adults residing in Lorestan province in order to identify relationship between them, simultaneously. Understanding this relationships are vital for developing the most appropriate interventions for improving or preserving QoL, social health and social support for older adults. This can be resulted in appropriate policies using the priority aspects of social life of older adults.

\section{Method \\ Data}

This cross-sectional study was conducted on 800 older adults living in Lorestan, Khoramabad city (in 3 urban areas) in 2018. Participants were selected via Stratified random sampling. For sample size in structural equation modeling, most studies recommend using sample sizes of at least 5 or 10 cases per parameters (15). Based on calculation, the sample size recruited was 750 respondents; however the actual sampling size was increased to 800 respondents to avoid attrition bias. All participants were interviewed at public places such as libraries, mosques and parks. Questionnaires were completed by three trained research personnel and face-to-face interview.

\section{Measures NSSQ}

Social support was measured by the Norbeck Social Support Questionnaire (NSSQ)(13). In this scale, the total social support score ranges between 0 and 76 with higher scores indicating superior feeling of support. Cronbach's alpha coefficient of reliability was 75. This scale included five subscales measuring tangible, emotional, functional and structural support and loss. Tangible support score ranged between 0 and 16 and measured the level of help available to the respondent in doing their daily chores in case he or she was confined to bed. Functional support score ranged between 0 and 12 and measured the amount of functional the respondent receives. Structural support score ranged between 0 and 16 and determined the level of the respondent's involvement in positive social interaction, such as having someone to have a good time and/or relax with. Emotional support score ranged between 0 and 32 and determined the extent to which the respondent had someone to advise them in a crisis, give them information, to confide in and talk to, or to understand their problems.

\section{Social health}

In most of the studies done on the social health (well-being) in Iran, the translated form of Keyes model was used. The reliability and validity of the questionnaire of KEYES model was also evaluated in Iran by Babapour (Cronbach's alpha $=0 / 78)(3,16)$. KEYES proposes the social well-being dimensions according to the health pattern. This scale included five subscales measuring social integration, social acceptance, social contribution, social actualization and social coherence. On a scale from one (totally disagreed) to five (totally agreed), respondents described how they functioned. Negative items (20 out of 33) were reversed-coded the total social health score ranges between 0 and 100 with higher scores indicating superior feeling of health. Confirmatory factorial analysis showed the best fitness for this questionnaire (17)

\section{Quality of life}

QoL was measured by Lipad scales. The Lipad quality of life scale includes physical, emotional, social and sexual performance, self-care, depression and life satisfaction. The reliability and validity of this questionnaire was also evaluated good by Hesamzadeh (Cronbach's alpha $=0.83)(18)$.

Also demographic and socioeconomic indicators including gender, marriage status, income and insurance were collected.

\section{Data Analyses}

Structural equation modeling (SEM) was used to examine the relationships among social health, QoL and social support. Multiple criteria of goodness-of-fit statistics were used in the assessment of model fit: (a) the Root Mean Square Error of Approximation (RMSEA); (b) the normed and non-normed fit indices (NFI, NNFI); and the Comparative Fit Index (CFI). Values of RMSEA less than 0.05 indicate good fit, and values as high as 0.08 represent reasonable errors of approximation, values ranging from 0.08 to 0.10 indicate a mediocre fit, and those greater than 0.10 indicate a poor fit. Regarding NFI, NNFI and CFI, each provides a measure of complete co-variation in the data, with a value $>0.90$ indicating an acceptable model fit(19).

\section{Ethical considerations}

This study received approval from the ethics committee of Isfahan University of Medical Sciences (Code= IR.MUI.RESEARCH.REC.1397.059). Before the data collection, all participants were made aware of the purposes of the study. Oral and written consents were obtained and they were assured that the collected data would only be used for research aims. 


\section{Results}

The majority of the participants were men $(51 \%)$ and fifty nine percent of the respondents were female. A majority of the participants $(62 \%, n=497)$ were married. Most of the study participants had income below 200 dollars $(90 \%, \mathrm{n}=725)$.

As indicated in Table 1, there were significant correlation among perceived social health and social support, insurance and income. Quality of life had a positive correlation with marriage status and income.

Table 1: Relationship between the main variables

\begin{tabular}{|c|c|c|c|c|c|c|}
\hline & Income & $\begin{array}{c}\text { Marriage } \\
\text { status }\end{array}$ & Insurance & variable & & \\
\hline & P value & $\mathrm{r}$ & P value & $\mathrm{r}$ & P value & $\mathrm{r}$ \\
\hline Social Health & $* 0.01$ & 0.482 & 0.45 & 0.375 & $* 0.001$ & 0.751 \\
\hline Quality of life & $* 0.001$ & 0.854 & $* 0.000$ & 0.590 & 0.39 & 0.621 \\
\hline Social Support & $* 0.03$ & 0.391 & 0.18 & 0.218 & $* 0.002$ & 0.512 \\
\hline
\end{tabular}

Figure 1: Standardised Estimates of the Structural Relationships Among social support, social health and quality of life

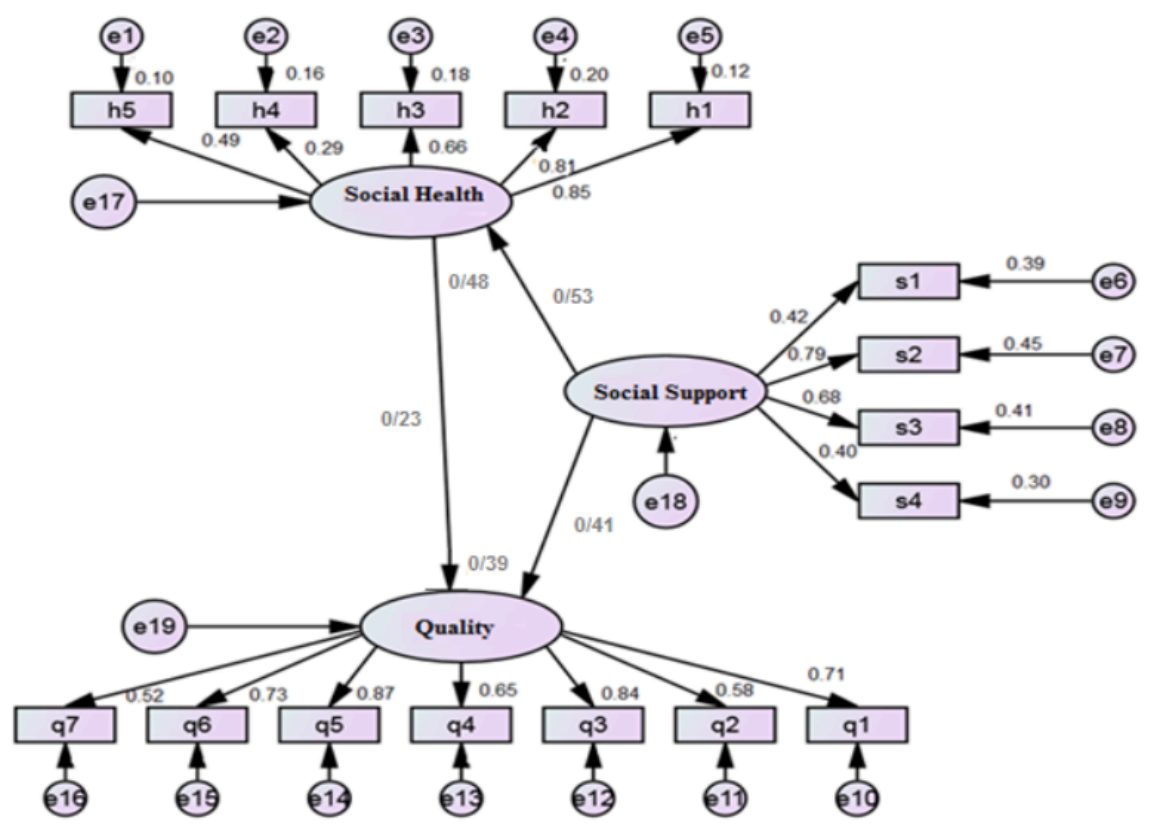

Because the measurement model had been acceptable from the CFA analysis, the hypothesized theoretical model was analyzed through SEM using AMOS 8. SEM was performed in this study to confirm the goodness-of-fit of the structural model. As in the case of the measurement model, the global fit indices were computed to measure how well the hypothesized model fits the data. Overall, the fit indices suggested that the structural model was an acceptable fit to the data.

RMSEA (0.043) value falls within acceptable values of $0.05-0.07$. In addition, all of the fit indices for the structural model were above the acceptable 0.90 level $(C F I=0.90, G F I=0.94, A G F I=0.91)$.

Table 2: Results of structural model testing

\begin{tabular}{|c|c|c|c|c|c|c|}
\hline Path & Total effect & .C.R & $\mathrm{p}$ & $\begin{array}{c}\text { Determination } \\
\text { Coefficient }\end{array}$ & $\begin{array}{c}\text { Direct } \\
\text { effect }\end{array}$ & Indirect effect \\
\hline $\begin{array}{c}\text { Social support on social } \\
\text { health }\end{array}$ & 0.37 & 3.41 & 0.000 & 0.48 & 0.53 & - \\
\hline Social support on QoL & 0.47 & 2.19 & 0.04 & 0.39 & 0.41 & 0.06 \\
\hline Social health on QoL & 0.23 & 3.85 & 0.001 & - & 0.23 & - \\
\hline
\end{tabular}

Table 2 presents the estimated standardized direct and indirect effects for each of the structural model, and all paths were found to be significant $(p<0.05)$, indicating that the 3 hypotheses were supported. First, perceived social support had a significant positive impact on social health $(p<0.05)$. Forty eight percent of social health changes are explained by social support. Second, perceived social support had a positive direct and indirect influence on QoL ( $p<$ 0.05). Thirty nine percent of QoL changes are explained by social support. Third, the proposed link between QoL and social health was positive and significant $(p<0.05)$. Diagram of the SEM is presented in Fig. 1. 


\section{Discussion}

This study was the first attempt to investigate the relationships between social support, QoL, and social health in older adults in Lorestan province. Furthermore, the study used structural equation technique to examine the complex structure of the relationships among variables study. A large number of empirical studies have been conducted to investigate factors influencing social health, social support and QoL among older adults.

In this study, Forty eight percent of social health changes are explained by social support. This is consistent with the findings of Garoosi (20),

Berkman (21) and Golden (22). This finding suggests that the lack of social support can have a detrimental impact on their social health. Respecting elderly and having them live with family members (children etc.) is common in Lorestan culture. Living at home with a spouse and children and having social security all positively affected on social health.

In this study, Thirty nine percent of QoL changes are explained by social support and social health. The results of this study can help create more effective health and education programs for the older generations to improve their QoL. According to Lasheras(2001) lower social health level is associated with unhappiness, poor social relationships and poor self-esteem among the elderly(23).Social support provide positive and rewarding experiences for individuals, which will result in an increase in selfesteem(8) . In general, social support and quality of life for the older adults are due to two factors: Access to family, friends, neighbours and relatives, and the interactivity of the elderly with individuals and members of his social network. Different types of social networks have different abilities in providing social support(24). According to Green (2009) and Springer (2011), loneliness, social isolation and low level of social participation from addressing social health, reduce QoL(22).

In Iran, the cultural and religious background do not allow the older adults to be left alone and encourages younger people to take care of their elderly parents; while in developed societies often older people value their independence and may prefer to live alone(25). In Lorestan province, the care of elderly people in nursing homes or institutions is largely deemed unacceptable by the general public. However, due to recent changes of family size, migration and accommodation problems, there is a trend to transfer older adults to nursing homes for better care(1). Diversity in social support (low to high level) has an important impact on QoL and social health especially in older adults with disability or illness.

Also, there was a significant relationship between social health and QoL. Increasing satisfaction in the community will increase their QoL and increase the sense of social responsibility. According to the Berkman, high QoL is felt when the basic needs of the elderly are met and they have opportunities to achieve their goals(21).
Due to the increasing population of the elderly and the high costs of health and treatment, the role of social support in improving the quality of life and social health of the elderly should not be ignored. All kinds of social support are very valuable, low-cost and free resources that can be easily provided for the elderly. It is necessary that policy makers, planners and families provide resources for elderlies. Also, families should be aware of the importance of emotional support and social networks. We hope that our findings can help to begin increasing the awareness and understanding surrounding the importance of social support in health and quality of life.

\section{Conclusion}

These findings provide a detailed conceptual framework to guide future research for older adults. In particular, unique information is offered on the importance of considering social support and social health factors for QoL in older person. Social programs targeted to older populations are needed to acknowledge their different needs and resources. It also would be well that personal resources (i.e. a high sense of coherence) and external resources (i.e. adequate formal and informal social support) counteract losses in other areas such as failing health and limitations due to health problems. The findings may also point in the direction that social resources and social networks are sensitive to declining functional ability. To sum up, this study indicate that it can be beneficial to develop interdisciplinary (i.e. health and social care) programs as these may have the possibility to offer a wider variety of interventions and services targeting more aspects of older adults's lives.

The study had several limitations. The findings lack external validity as the data come from one province. Therefore we will not be able to generalize these findings to other provinces. Mood states and physical health of people at the time of answering QoL questions also can affect responses. Also, research should be carried out for men and women separately. It is suggested that in future studies, cultural factors also be considered. Additionally, qualitative studies such as in-depth interviews with older adults can be used to have a better understanding on the topic.

\section{Acknowledgements}

The authors would like to express their gratitude to all older adults for participating to this study.

\section{References}

1. Teymoori F, Dadkhah A, Shirazikhah M. Social welfare and health (mental, social, physical) status of aged people in Iran. Middle East Journal of Age and Ageing. 2006; 3(1):39-45

2. Gavrilov LA, Heuveline P. Aging of population. The encyclopedia of population. 2003;1:32-7

3. Torani S, Delgoshaei B, Hosseini AF, BibiZiaefar H, Raadabadi M. Relationship between Social Wellbeing and Health Related Quality of Life Level 
among Senior Retirees of Tehran University of Medical Sciences. Asian Social Science. 2015;11(18):116

4. Statistical Center of Iran. The report of the 2015 population census. 2015, Available from: https:// www.amar.org.ir/Detailed results of census-province

5. Ghasemi H, Harirchi M, Masnavi A, Rahgozar M, Akbarian M. Comparing quality of life between seniors living in families and institutionalized in nursing homes. Social Welfare Quarterly. 2011;10(39):177-200.

6. Tajvar M, Arab M, Montazeri A. Determinants of health-related quality of life in elderly in Tehran, Iran. BMC public health. 2008;8(1):323.

7. Heravi-Karimooi M, Anoosheh M, Foroughan M, Sheykhi MT, Hajizadeh E. Understanding loneliness in the lived experiences of Iranian elders. Scandinavian journal of caring sciences. 2010;24(2):274-80

8. Bakhtiyari M, Emaminaeini M, Hatami H, Khodakarim S, Sahaf R. Depression and perceived social support in the elderly. Iranian Journal of Ageing. 2017;12(2):192-207.

9. Gigliotti E. A confirmation of the factor structure of the Norbeck Social Support Questionnaire. Nursing research. 2002;51(5):276-84

10. Gallicchio L, Hoffman SC, Helzlsouer KJ. The relationship between gender, social support, and health-related quality of life in a community-based study in Washington County, Maryland. Quality of life research. 2007;16(5):777.

11. Bowling A. Ageing well: Quality of life in old age: McGraw-Hill Education (UK); 2005.

12.Farquhar MC. Older People's Definitions of Quality of Life and the Relevance of Various Scales: University of London; 2009.

13. Norbeck JS, Lindsey AM, Carrieri VL. The development of an instrument to measure social support. Nursing research. 1981

14. Alipour F, Sajadi H, Forouzan A, Nabavi H, Khedmati E. The role of social support in the anxiety and depression of elderly. Sālmand. 2009;4(1)

15. Wolf EJ, Harrington KM, Clark SL, Miller MW. Sample size requirements for structural equation models: An evaluation of power, bias, and solution propriety. Educ Psychol Meas 2013; 73: 913-934

16.Babapour Kheiroddin, J., Toosi, F., Hekmati, I. (2010). 'Study of Determinant Factors Role of Students' Social Well-Being', Journal of Modern Psychological Researches, 4(16), pp. 1-19

17.Baghsorkhi AR, Refahi Z, Jahedi S. The relationship between social health and self-effcacy mediated by personality characteristics of graduate students. Journal of Novel Applied Sciences. 2013;2:36-40

18. Hesamzadeh A, Maddah S B, Mohammadi F, Fallahi Khoshknab M, Rahgozar M. Comparison of Elderlys "Quality of Life" Living at Homes and in Private or Public Nursing Homes. sija. 2010; 4 (4)

19. Raykov T, Marcoulides GA. A first course in structural equation modeling: Routledge; 2012.

20.Garousi S, Safizadeh H , Samadian F. The study relationship between social support and quality of life among elderly people in Kerman, Jundishapur Medical Journal 2012 (Issue 3).

21.Berkman LF, Glass T. Social integration, social networks, social support, and health. Social epidemiology. 2000;1:137-73.

22. Golden J, Conroy RM, Bruce I, Denihan A, Greene E, Kirby M, et al. Loneliness, social support networks, mood and wellbeing in communitydwelling elderly. International Journal of Geriatric Psychiatry: A journal of the psychiatry of late life and allied sciences. 2009;24(7):694-700.

23.Lasheras AMP, Carmen Casado, Serafina Fernandez, Cristina. Effects of education on the quality of life, diet, and cardiovascular risk factors in an elderly Spanish community population. Experimental Aging Research. 2001;27(3):257-70.

24.Lei P, Xu L, Nwaru B, Long Q, Wu Z. Social networks and health-related quality of life among Chinese old adults in urban areas: results from 4th National Household Health Survey. Public health. 2016;131:27-39

25.Bowling A, Gabriel Z, Banister D, Sutton S. Adding quality to quantity: Older people's views on their quality of life and its enhancement. Ikääntyvien Arjen Ja Elämänlaadun Tutkimus. 2002;9. 